\title{
Complutum
}

ISSN: 1131-6993

\section{Últimos trabajos arqueológicos en la ciudad carpetano-romana del Cerro de la Virgen de la Muela (Driebes, Guadalajara)}

\author{
Emilio Gamo Pazos ${ }^{1}$; Javier Fernández Ortea²; Jerónimo Sánchez Velasco ${ }^{3}$
}

Recibido: 26 de enero de 2017 / Aceptado: 30 de octubre de 2018.

Resumen. Presentamos los resultados de la investigación arqueológica realizada en el Cerro Virgen de la Muela (Driebes) que demuestran la existencia de una ocupación prolongada desde el Bronce Final en la que destaca el oppidum carpetano y la posterior ciudad romana, que consideramos es la antigua Caraca. Los trabajos de un equipo multidisciplinar han permitido certificar la importante entidad del enclave y su secuencia cultural.

Palabras Clave: Carpetanos; Caraca; romanización; Guadalajara; oppidum.

[en] Recent archaeological research in the carpetanian and roman city of Cerro de la Virgen de la Muela (Driebes, Guadalajara)

\begin{abstract}
We show the results of the archaeological research carried out on the Cerro Virgen de la Muela (Driebes), which show the existence of a prolonged occupation from the Late Bronze Age, in which is important the carpetanian oppidum and the later Roman city, probably Caraca. The work of a multidisciplinary team has made it possible to certify the importance of the settlement and its cultural sequence.
\end{abstract}

Key words: Carpetani; Caraca; romanization; Guadalajara; oppidum.

Sumario: 1. Introducción. 2. Trabajos realizados. Metodología aplicada. 3. La información obtenida. 4. La secuencia cultural del yacimiento. 5. Consideraciones finales.

Cómo citar: Gamo Pazos, E.; Fernández Ortea, J.; Sánchez Velasco, J. (2018): Últimos trabajos arqueológicos en la ciudad carpetano-romana del Cerro de la Virgen de la Muela (Driebes, Guadalajara). Complutum, 29(1): 9-22

\section{Introducción}

En el Cerro de la Virgen de la Muela se sitúa un núcleo urbano de época carpetana, romana republicana y altoimperial de 8 ha de extensión, que creemos era Caraca, con precedentes poblacionales en el Bronce Final y la I Edad de Hierro ${ }^{1}$. Se ubica al sur de la localidad de Driebes (Guadalajara $)^{2}$, en la comarca de la Alcarria Baja.

El yacimiento está emplazado sobre un amplio cerro amesetado con una altitud media de
610 msnm., se sitúa en la orilla derecha del Tajo, sobre un amplio meandro y está delimitado por barrancos con cursos de agua irregulares, siendo un punto óptimo para el asentamiento antrópico. Esta visión queda reforzada por la situación estratégica del enclave: domina el Tajo desde el norte, el arroyo del Barranco está al este, el arroyo Salobre al oeste y una fértil vega a sus pies. Actualmente la superficie del yacimiento se emplea como tierra para el cultivo de secano.

\footnotetext{
Equipo Arqueológico Caraca. emiliogamo@hotmail.com.

2 Equipo Arqueológico Caraca. javierfernandezortea@gmail.com

3 IES Santos Isasa (Montoro, Córdoba). jsanchez70@us.es
} 
Durante la construcción del canal de Estremera en 1945, fueron localizados a los pies del Cerro de la Virgen de la Muela dos conjuntos de plata, muy próximos entre sí con un peso total de 13,8 kg distribuidos en 1480 fragmentos que incluye: tortas de pesos, recipientes, lingotes, sortijas, torques, fíbulas, y 19 monedas, todas partidas menos una (San Valero 1945). El tesoro se expone actualmente en el Museo Arqueológico Nacional.
Pese a la importancia de esta ocultación argéntea, el yacimiento no ha sido excavado y es conocido únicamente por prospección. En las décadas de los años 70 y 80 del pasado siglo Abascal (1982: 80) y Sánchez-Lafuente (1982) realizaron las primeras prospecciones en el lugar ${ }^{3}$. Estos investigadores señalaron que se trata de un yacimiento relevante y que es posible que se correspondiera con la antigua Caraca.

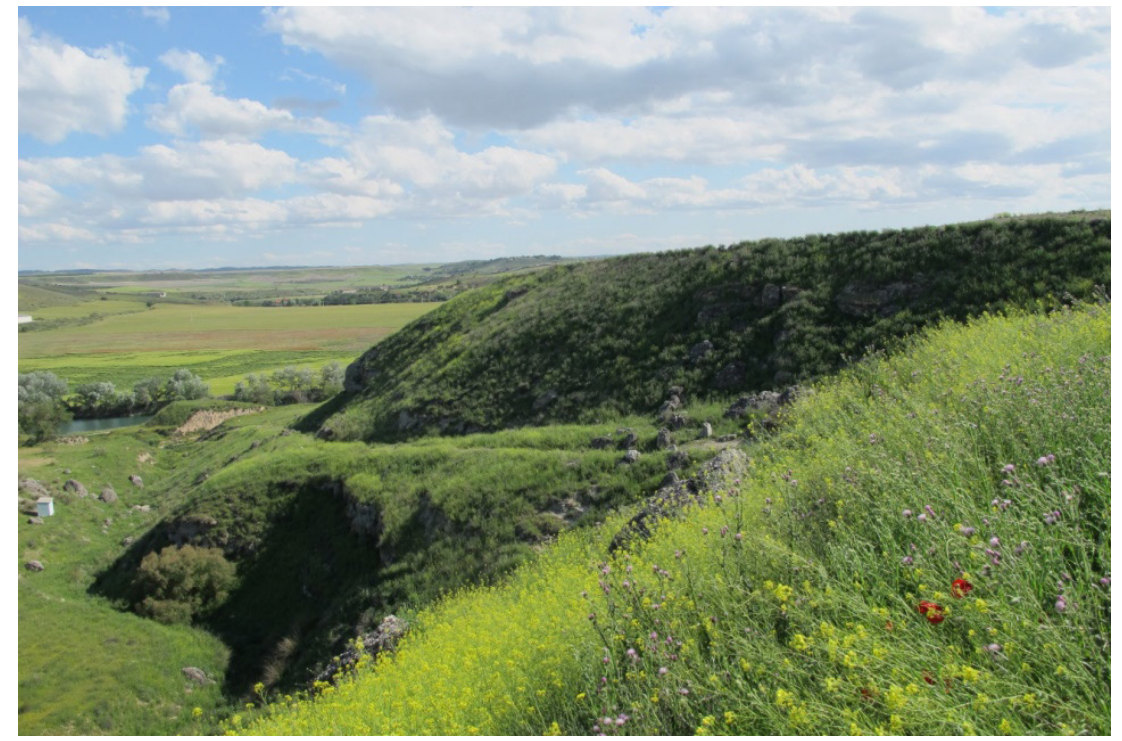

Figura 1. Cerro de la Virgen de la Muela visto desde el Noreste, se observa el trazado de la vía Carthago Nova-Complutum.

En el marco de la Tesis Doctoral de uno de nosotros (Gamo 2015) quisimos revisar los restos carpetanos y romanos procedentes del yacimiento conservados en el Museo de Guadalajara ${ }^{4}$.

En otoño de 2016 la entidad de los restos carpetanos y romanos nos llevó a plantear la realización del proyecto de investigación: "Prospección arqueológica intensiva y geotécnica del Cerro de la Virgen de la Muela en Driebes (Guadalajara)", financiado por la Junta de Comunidades de Castilla-La Mancha $^{5}$, con cofinanciación del Ayuntamiento de Driebes y la Asociación de Amigos del Museo de Guadalajara.

También creímos importante confirmar la existencia de un acueducto romano que demuestra la entidad de la ciudad. Realizamos la comprobación in situ6 de las características, cronología y extensión de estos restos mediante una prospección superficial sin sondeos.

\section{Trabajos realizados. Metodología aplicada}

Antes de acometer los trabajos de campo, realizamos un profundo análisis de la toponimia local, la cartografía y fotografía aérea histórica disponible. Las tareas de campo se estructuraron en dos fases, en las que hemos combinado las actuaciones arqueológicas tradicionales con las nuevas tecnologías que están aportando resultados muy significativos. El objetivo marcado fue contrastar los resultados de ambas y con la información obtenida, evaluar la entidad del yacimiento, su marco cronológico y su contexto histórico. Teniendo en cuenta las posibilidades técnicas de las prospecciones no invasivas, planteamos estas actuaciones de carácter no agresivo con el yacimiento, ya que no se realizaron excavaciones.

En la primera fase realizamos una prospección intensiva de cobertura total sin sondeos, 
durante la que se recuperaron abundantes materiales que quedaron georreferenciados con un GPS Garmin etrex30. De este modo pudo dibujarse un plano de dispersión de los diferentes materiales, a partir de los cuales hemos podido distinguir tres sectores bien diferenciados.

En la segunda fase, se realizó un estudio de imagen aérea en RGB mediante un dron cuadricóptero modelo md4-1000 de la casa Microdrones. Se ha empleado una cámara semireflex con 14 megapíxeles de resolución y se ha obtenido un GSD en $\mathrm{x}$ e y de $5 \mathrm{~cm}$ y 8 $\mathrm{cm}$ en z. Por tanto se ha obtenido un modelo digital del terreno y una ortofoto con $5 \mathrm{~cm}$ de pixel. A continuación se realizó una prospección geofísica con un georrádar multicanal o georrádar 3d Stream X de la casa IDS Ingeniería del Sistemi con una frecuencia nominal de $600 \mathrm{MHz}$ y se ha alcanzado una profundidad de 1,3 m debido a las características del suelo y la cantidad de humedad que, en parte, ha atenuado la señal. Se obtuvieron 11 secciones de georrádar espaciadas $8 \mathrm{~cm}$ por cada transecto. Se han realizado un total de 170 transectos que arrojan un total de 1.870 secciones de georrádar para cubrir un área de $10.322 \mathrm{~m}^{2}$. Estos trabajos fueron realizados por el CAI de Arqueometría y Análisis Arqueológico en colaboración con el Departamento de Física de la Tierra, Astronomía y Astrofísica I (Sección departamental de Astronomía y Geodesia), de la Facultad de Matemáticas de la UCM.

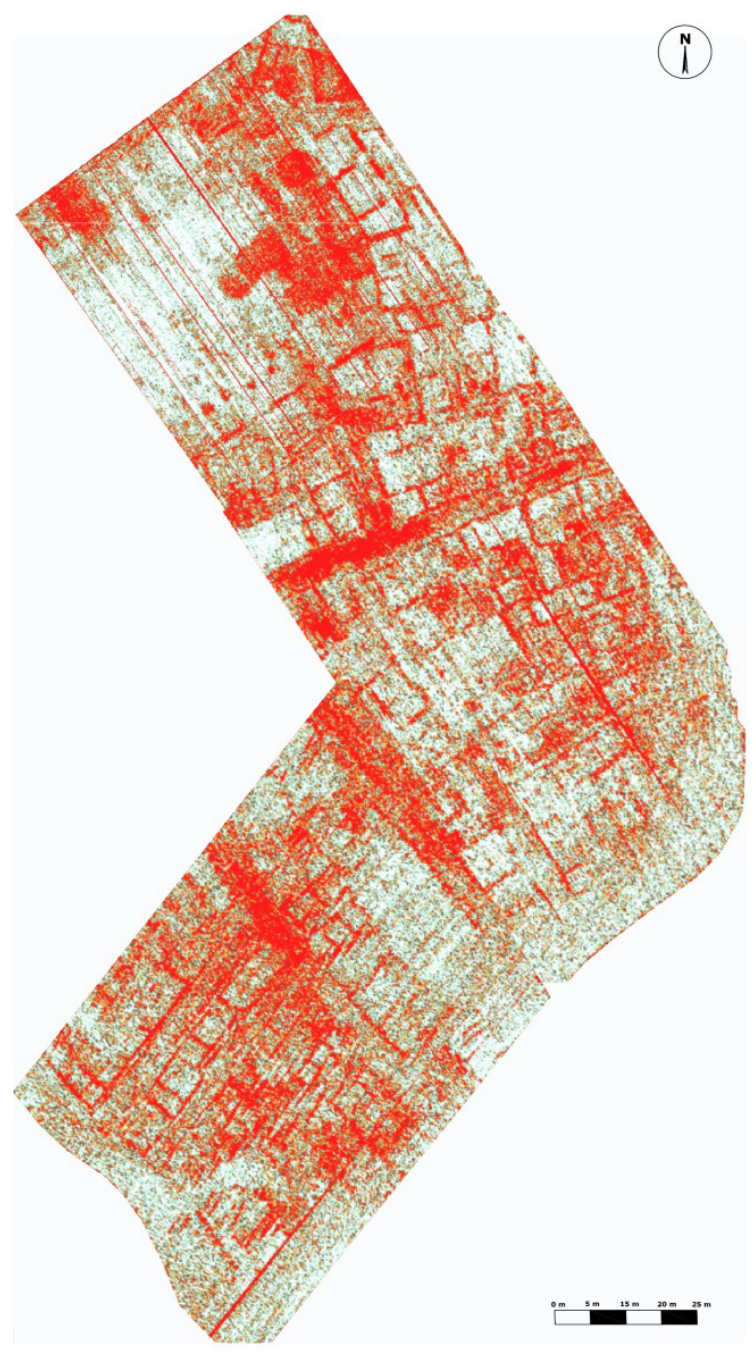

Figura 2. Resultado de la prospección geofísica con georrádar. 


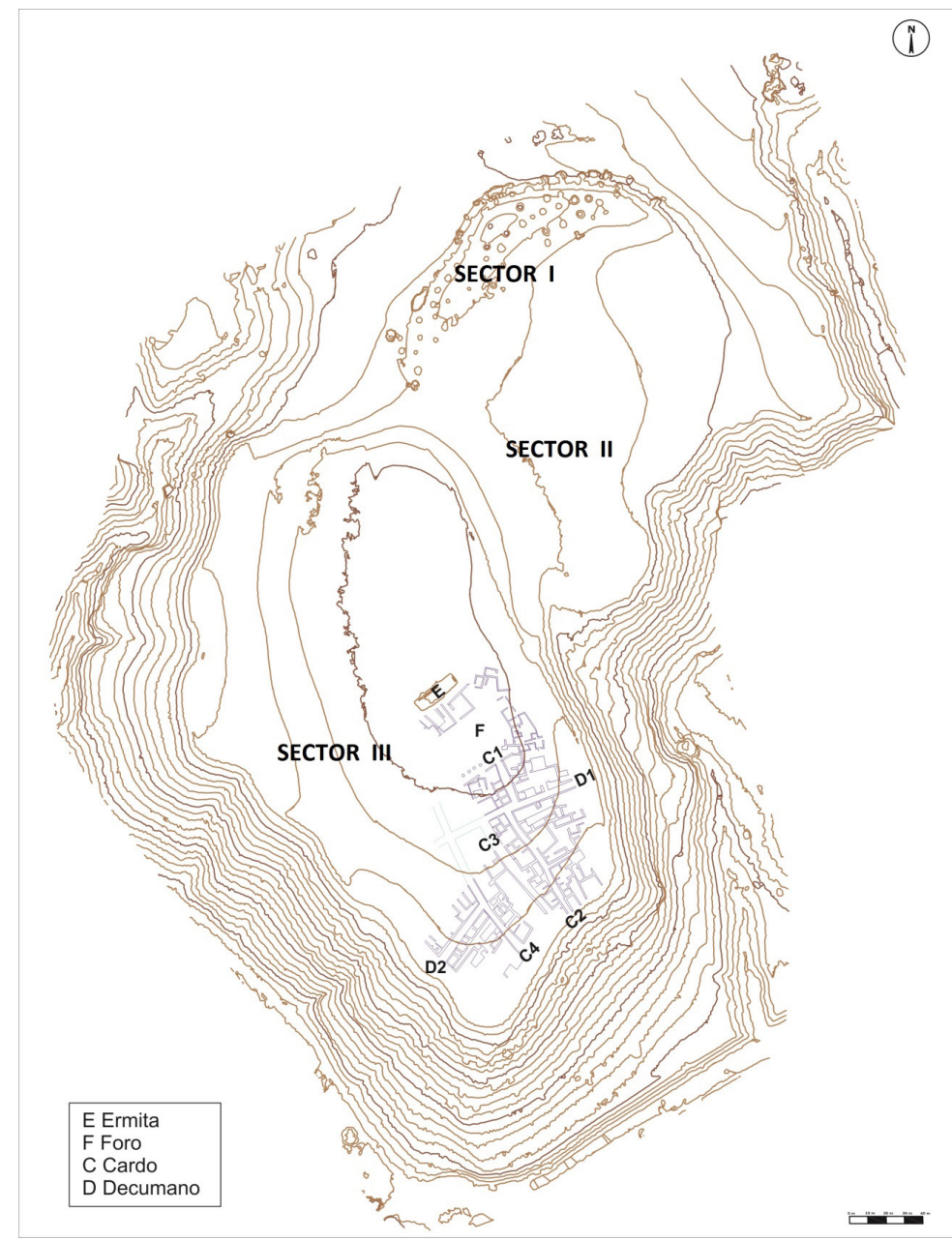

Figura 3. Interpretación de las estructuras identificadas en la prospección geofísica.

\section{La información obtenida}

En la superficie del yacimiento hemos documentado una gran cantidad de material cerámico, así como estucos, vidrio y sílex. La distribución de estos hallazgos ha permitido describir una estratigrafía horizontal del yacimiento, en la que identificamos con claridad tres sectores.

-Sector 1: Corresponde a la zona noreste y la más elevada, denominada "Cerro Esporteado", ocupado por olivos. La tradición atribuye a este paraje haber sido la puerta de la ciudad y quizás el actual bancal esté sobre estructuras defensivas antiguas. En este promontorio se identifican las piezas más antiguas del yacimiento: talla lítica, cerámica de la Edad del Bronce, I Edad del Hierro y carpetana (pintada, jaspeada y estampillada).

-Sector 2: Es una amplia terraza en el sureste, ocupada por terrenos de cultivo de secano.
Cronológicamente parece la continuación inmediata del "Cerro Esporteado" ya que se recuperaron cerámicas carpetanas, un pondus y una fusayola, así como cerámica romana republicana. Aquí es donde se concentra la mayoría de las escasas cerámicas romanas de barniz negro y ánforas Dressel 1. También encontramos cerámica común romana, pintada de tradición indígena, T.S.H., fragmentos de dolia, tégulas e ímbrices.

-Sector 3: Es la amplia superficie amesetada hacia el oeste, empleada en cultivo de secano. Destaca claramente al norte un espacio ocupado por materiales romanos de almacenaje (dolia), cocina y construcción (tégulas e ímbrices). Tras el cambio de cota, al sur de las ruinas de la ermita de la Virgen de la Muela, los materiales son más finos con presencia abundante de sigillata (itálica, gálica e hispánica), común romana y vidrio. Al sur de la ermita se ha registrado además de cerámica muy 
abundante de todos los tipos altoimperiales, grandes cantidades de estucados rojos, negros, amarillos y azules, así como restos de opus signinum. También se han recogido fragmentos de cerámica carpetana y romana de barniz negro.

Las ruinas de la ermita están colmatadas por grandes sillares yesíferos y hay tres fustes de columna reutilizados en las paredes norte y sur, dos de ellos en una ampliación con posterioridad al edificio primitivo. En uno de los tambores se mantiene incluso un número grabado. En esta zona, existen sillares de grandes proporciones (alcanzando los dos metros de longitud), pertenecientes a edificaciones de carácter público, que fueron retirados de su posición original por los labradores durante las tareas agrícolas. Algunos de ellos presentan un rebaje almohadillado, el negativo de una grapa y marcas de cincelado. En la propia localidad de Driebes existen en las fachadas de distintos edificios actuales, columnas y sillares reutilizados como material constructivo quizás procedentes de este lugar. También se han documentado en el yacimiento fragmentos de lapis specularis y de estuco de gran calidad con combinaciones de pintura de color rojo, negro, azul y amarillo, especialmente al sur de la ermita.

En este sector es donde hemos realizado la prospección con georrádar que ha permitido conocer numerosos detalles urbanísticos de la ciudad. Evidentemente se trata de una interpretación provisional, a la espera de la necesaria excavación que confirme los resultados de este estudio. Los datos obtenidos, contrastados en un intenso trabajo de laboratorio llevado a cabo por los miembros del CAI y del equipo arqueológico, han permitido trazar parte de la planta de esta ciudad, donde sólo se han señalado aquellas estructuras constructivas que se distinguen con total seguridad (Fig. 3).

La mayoría de estas estructuras constructivas están a una profundidad homogénea (a partir de $40 \mathrm{~cm}$ desde la superficie), salvo en algunos lugares puntuales con estructuras a diferente profundidad y con orientación distinta, que pensamos corresponderían a una fase previa.

Los espacios públicos de tránsito aparecen claramente definidos, perfilándose una plaza, que por sus dimensiones y forma creemos que es el foro de la ciudad (Fig. 3, F). No sabemos las medidas exactas de este espacio público ya que en la zona más occidental no se ha pros- pectado con georrádar, aunque creemos que se trataría de una plaza rectangular, como la mayoría de los foros hispanos.

Al norte de este espacio, que queda delimitado por las ruinas de la ermita (Fig. 3, E), aparecen dos edificios rectangulares de gran tamaño. El más occidental de ellos parece corresponder con la antigua casa del santero de la ermita, que todavía era visible en la foto aérea del Vuelo Americano de 1956-57 (Serie B). La zona oriental del foro es una amalgama no muy definida de estancias pequeñas y consecutivas. La fachada sur de la plaza cuenta con una columnata que indica un pórtico, limitado por un Cardo (Fig. 3, C1). Este pórtico daría acceso a un edificio rectangular de una amplia fachada que cuenta con unos muros internos de orientaciones y profundidades muy dispares. Entre los edificios del norte del foro y la zona porticada del sur hay unos $26 \mathrm{~m}$ de distancia, lo que lo convertiría en una plaza de amplias dimensiones, si lo comparamos con otros foros como el de Pollentia (Arribas y Tarradell 1987: 124) y Ercavica (Lorrio 2001: 106-108) que tienen prácticamente las mismas dimensiones en su lado menor, el foro cuadrangular de Torreparedones (Morena y Moreno 2010: 452) que tiene $22 \mathrm{~m}$ de norte a sur, casi igual $(23 \mathrm{~m})$ que la plaza del foro de Emporion (Sanmartí 1987); la de Baelo Claudia (Pelletier et alii 1987: $165)$ es más grande aún, ya que su lado menor es de $33 \mathrm{~m}$. Todos ellos son de época altoimperial temprana, menos el de Emporion, que es republicano.

La zona norte de este foro parece contar con sendas plataformas, que podrían corresponder con el basamento de varios templos como en Baelo Claudia (Pelletier et alii 1987; Sillières 1997: 87-91) o de un templo y una curia como en el foro de Torreparedones (Morena y Moreno 2010). Los datos que tenemos de la zona oriental indican la sucesión de estancias más pequeñas cuya interpretación no es unívoca, que pensamos podrían ser edificios de carácter público o bien tabernae. La fachada sur es más compleja de interpretar, debido a la presencia de muros de fases diferentes, y la existencia de un Cardo (Fig. 3, C1) que da acceso a la plaza. La zona porticada sur del foro pudo ser un edificio de grandes dimensiones, tal vez una basílica, aunque es posible que sea sólo un pórtico como en Ercavica (Lorrio 2001: 109). Frente a la zona de templos era habitual ubicar una basílica, centro de la vida cívica y judicial de la ciudad (Jiménez 1987: 176). A espaldas de 
ésta, la insula delimitada al este por el Cardo 1 y el Decumanus 1 estaría ocupada por una serie de tabernae bien definidas.

Resulta difícil atisbar la funcionalidad de la insula que aparece delimitada al oeste y al sur por del Cardo 1 y el Decumanus 1 respectivamente. Desde éste hay un acceso a un gran patio.

Otra insula queda definida por el Cardo 2 al oeste y el Decumanus 1 al norte. La insula queda dividida por un callejón bastante estrecho. La parte septentrional de la insula está ocupada por un gran edificio que se articula en torno a un patio de forma ligeramente trapezoidal. La proximidad al foro y la existencia de ese gran patio son características que nos llevan a plantear que se trata de un macellum (De Ruyt 1983: 328 y 367-372; Torrecilla 2007: 466). El patio ligeramente trapezoidal tiene similitudes con el macellum de Celsa (Beltrán 1991), aunque su distribución interna tiene cierto parecido con el de Torreparedones (Morena et alii 2012). Al sur del estrecho callejón la amalgama de muros y su indefinición nos impiden adscribir una funcionalidad para esta zona.

Entre el Cardo 2 y 3 queda delimitada una alargada y estrecha insula. Las dimensiones de las estancias son realmente pequeñas en su mayor parte, condicionadas por el complejo encaje entre dos calles muy próximas entre sí. Creemos que puede tratarse de una zona artesanal, o de almacenaje, porque vemos difícil que esta sucesión de pequeñas estancias en sentido norte-sur sean espacios domésticos. Tanto en el Decumanus 1 como en el Cardo 3 se observa en el centro de la calle la existencia de alcantarillado.

Entre el Cardo 3 y el 4 se vislumbra un gran espacio abierto, delimitado por un muro que sirve de fachada al Cardo 3. Al oeste de este gran patio, hay una abigarrada sucesión de pequeñas estancias que no parece tener acceso desde la calle (Cardo 4).

Aunque la zona suroccidental está más desdibujada por encontrarse en la pendiente del cerro, parece articulada por el Decumanus 2 (Fig. 3 , D2). Al sur hay un gran muro que se prolonga a lo largo de toda la calle y que articula una serie de estancias alargadas con muros incluso retranqueados, que corresponderían a espacios domésticos. Al norte del Decumanus 2 hay un enorme edificio cuya fachada se encuentra articulada en una serie de pequeñas estancias consecutivas y casi todas (menos la más oriental), de dimensiones similares. Más al este es posible que estemos ante más salas de gran tamaño y un espacio abierto en la esquina oriental. Creemos que la sucesión de estancias de la parte norte de esta insula podría corresponder con la estructuración de unas termas, como las urbanas de Baelo Claudia (Gómez 2013) o las de Ercavica (Lorrio 2001: 73-84). De hecho, si analizamos la parte excavada en torno al tetrapylon de $\mathrm{Ca}$ parra (Río-Miranda e Iglesias 2002), aparecen unas termas flanqueadas por dos insulae ocupadas por posibles domus, caracterizadas por estancias alargadas en torno a un patio, que formalmente conforman un área similar a la de la ciudad romana de Caraca.

Con la planimetría proporcionada por el georrádar, estamos ante una ciudad romana altoimperial de tamaño medio, articulada en torno a un foro de importantes dimensiones que organiza una red viaria pública adaptada a la orografía. La existencia de fases anteriores carpetana y romana republicana es incuestionable, debido a la existencia de muros con diferente orientación y profundidad que hemos comentado anteriormente. En definitiva, en el foro aparecerían edificios correspondientes a las típicas funciones (Jiménez 1987) de estos espacios: así, al norte encontraríamos edificios religiosos; al este podríamos hablar de la fachada comercial; y al sur, la zona administrativa civil. Próximo al foro, en la insula formada por el Decumanus 1 y el Cardo 2, pudo existir un macellum. En la zona suroccidental del área documentada es posible que exista un edificio termal junto a una domus.

El acceso desde el sur a la ciudad es una rampa colmatada en la ladera este, denominada Camino de la Meseguera, que fue utilizado hasta épocas recientes como el paso de carruajes de arrieros. Es claramente un tramo de la vía Complutum-Carthago Nova, cuya importancia fue notable pues Carthago Nova fue capital de convento jurídico y posteriormente de la provincia Cartaginense, además de ser uno de los principales puertos de la Hispania romana para la exportación e importación de productos de la Meseta (Palomero 1987: 56). Es probable que fuera un itinerario superpuesto a caminos prerromanos (Almagro 1977: 101; Palomero 1987: 216).

\section{La secuencia cultural del yacimiento}

La distribución de material arqueológico en sectores claramente definidos en la prospec- 
ción de la superficie en una estratigrafía horizontal, así como la estratigrafía vertical que se desprende de la superposición de estructuras observadas en la prospección geofísica, permite trazar la secuencia cultural del yacimiento.

El cerro estuvo ocupado ya en el Paleolítico por la posible punta de tipo Levallois encontrada en el sector 1 del yacimiento y no sería extraño ya que se han documentado ocupaciones humanas desde el Paleolítico Inferior en el vecino término de Mazuecos, en los yacimientos de Dos Cerrillos y Camino Driebes (García Valero 2002).

Pero es a partir del Bronce Final cuando los asentamientos parecen continuos en el "Cerro Esporteado" según demuestran los materiales del Bronce Final y de la I Edad del Hierro del sector 1, similares a los de Pico Buitre, un típico enclave de los "poblados de ribera" (Valiente et alii 1986; Barroso 2002). El material es abundante, tanto lítico como cerámica a mano con digitaciones en el bordes, un mamelón perforado, etc...Similares también a los del cercano paraje de la Esteva (Almoguera), situado a 3' $6 \mathrm{~km}$ del yacimiento que estudiamos, en una llanura sobre la terraza fluvial situada en la margen derecha del río Tajo se ha excavado un hábitat de finales del II milenio a.C. (Vara y Martínez 2015: 34, n. 3).

Pero fue en época carpetana, en las postrimerías del siglo III a.C., cuando el asentamiento crece hasta convertirse en lo que consideramos que es un oppidum que ocupa la totalidad del "Cerro Esporteado" y la zona al sur de la vieja ermita. Esta ocupación carpetana está representada por abundantes cerámicas de diferentes tipos: a torno jaspeadas, con decoración monocroma de motivos geométricos -círculos y semicírculos concéntricos, bandas paralelas, melenas, etc...-, con decoración estampillada, así como bordes de dolia y tinajas de almacenamiento de gran capacidad, junto a un pondus y una fusayola.

Queda por confirmar la existencia de o no de un recinto amurallado de época carpetana. Pues los oppida carpetanos tienen, por norma general, unas fortificaciones notablemente menos monumentales que las de los celtibéricos, como se observa en el Llano de la Horca en Santorcaz (Ruíz Zapatero et alii 2012).

Este sería un oppidum más de los que en los valles medios del Henares, Tajuña y Tajo jugaron el papel de organizadores del territorio, centros de la comunidad política y lugar de referencia y/o residencia de los grupos diri- gentes de la sociedad. Una élite indígena que atesora en plata los excedentes derivados de su control sobre actividades agropecuarias. Esto parece probado por la aparición de ocultaciones argénteas en el contexto de la II Guerra Púnica en los oppida carpetanos como este que ahora estudiamos o El Castejón de Armuña de Tajuña (Ripollès et alii 2009). La vajilla de plata de estas ocultaciones está vinculada a la autorrepresentación de las élites en ceremonias sociales y religiosas, constatada por ejemplo en las bodas de Viriato (Diod., 33, 7, 1). En este sentido hay que interpretar los anillos de caballito localizados en Driebes (Almagro et alii 1999; Lorrio y Sánchez 2015).

Existe un intenso debate acerca de la cronología y función de la ocultación de Driebes (San Valero 1946; Raddatz 1969: 222; Villaronga 1993; Otero 2002), hallada al pie del cerro. García Bellido (2007: 220) defiende una fecha de cierre después del fin de la II Guerra Púnica y quizás en las primeras décadas del siglo II a.C. en los primeros conflictos con Roma, mientras que Chaves y Pliego (2015: 122 y 155) defienden una cronología anterior por la ausencia de monedas posteriores al año 207 a.C. (RRC, 57,2; 58,2). En cuanto a la función de la ocultación se ha propuesto que se trata de un depósito de platero por la fragmentación intencionada de piezas (San Valero 1945; Lorrio y Sánchez 2001). Otros investigadores han considerado que la presencia de tortas, plata picada y monedas cortadas tuvieron que cumplir un papel de metal al peso y por tanto dinero (Hildebrant 1993; Galán y Ruíz-Gálvez 1996; García-Bellido 1999; Otero 2002; Chaves 2012: 171). También existen propuestas de interpretación como un depósito votivo (Barril 2010).

Dadas las características de la ocultación y su ubicación en el área carpetana, creemos que debe abandonarse la denominación de "celtibérica" que tradicionalmente se le otorgaba (Cerdeño y Gamo 2014). En la Carpetania alcarreña se han encontrado otras producciones argénteas que pueden vincularse a talleres locales. Entre finales del siglo IV y comienzos del II a.C. los talleres plateros de la Alcarria -quizás ubicados en Driebes- crearon suntuosas fíbulas anulares con puente de cinta ancha repujada con motivos figurados, quizás míticos, de inspiración mediterránea y tratamiento centroeuropeo documentadas en Driebes y Armuña de Tajuña (González 1999: 98-102, no 15; Ripollès et alii 2009). Con 
cronología similar se documentan en Driebes, Armuña de Tajuña y Almoguera fíbulas tipo La Tène I, de pie vuelto $\mathrm{y}$ dos piezas con remate zoocéfalo, que también parecen de talleres locales (González 1999: 252-253, $\left.n^{\circ} 195,196,197,198,199\right)$. Habría que incluir la fíbula de la Muela de Taracena, tipo La Tène III con escena figurada, influenciada por modelos ibéricos meridionales (Angoso y Cuadrado 1981).
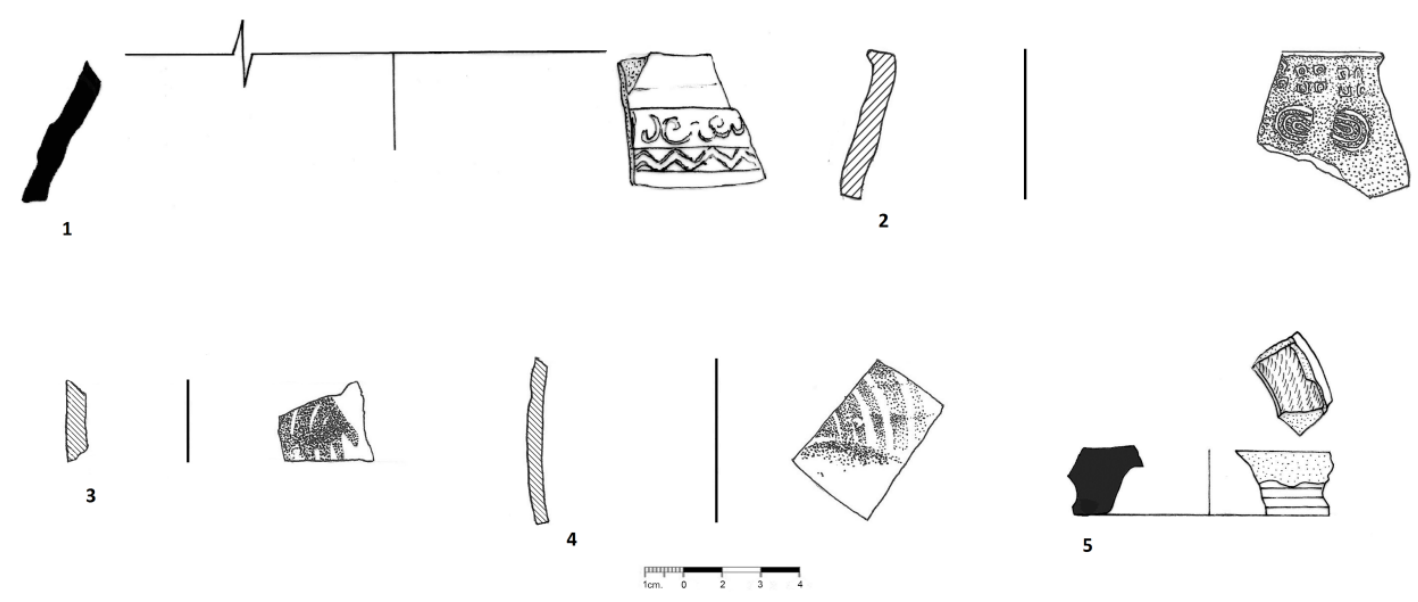

Figura 4. Cerámica carpetana y de barniz negro: 1 y 2-Cerámica estampillada, 3 y 4-Cerámica con decoración pintada, 5-Pie de campaniense C, probable copa Lamb. 17/ F 1255a 1 (Dibujos: M. Zorita y J. M. Higueras).

En época de los Barca la presencia cartaginesa llegó hasta estos territorios, especialmente tras la batalla del Tajo en el 220 a.C. que culminó con la derrota de la coalición indígena y la inclusión de la Carpetania en el ámbito de influencia púnica (Plb., 3, 13, 5; Liv., 21, 5, 2). La imposición de levas y exacciones por parte de los cartagineses llevó a revueltas en Carpetania (Liv., 21, 11), y, así mismo, la actuación de celtíberos y carpetanos como mercenarios de los bandos contendientes en la II Guerra Púnica produjo cambios socioeconómicos en estas comunidades (Gozalbes 2008: 44; Ruíz-Zapatero y Álvarez-Sanchís 2013: 346347; Torres 2013). La aparición de los oppida carpetanos se ha puesto en relación con la presión ejercida por púnicos y romanos a partir de fines de la tercera centuria (Almagro y Dávila 1995: 227).

Muchos oppida celtíberos y carpetanos continuaron ocupados hasta época sertoriana como es el caso del Llano de la Horca en Santorcaz (Ruíz Zapatero et alii 2012; Azcárraga 2015) que tiene, al igual que el Cerro de la Virgen de la Muela un período de prosperidad con cierta autonomía del poder romano.

El poblamiento en los dos siglos antes de la Era en este yacimiento queda bien atestiguado por la fíbula de la Tène final -de pie integrado en el puente y perfil trapezoidal, datada entre 140-70 a.C.- y por las monedas de las cecas de bolskan, sesars, seteis y sekaisa publicadas por González (1999: 25-26 y 385, n 410), además de la cerámica de barniz negro recogida en prospección. Entre los fragmentos de cerámica de barniz negro que hemos estudiado destacamos un galbo indeterminado de campaniense A media -190/180-100 a.C.- y un borde de barniz negro de Cales también de su fase media -130/120-90/80 a.C.-, que se trata de un cuenco similar a la serie 2974 de Morel. También documentamos un borde de campaniense A antigua -220-190/180 a.C.-, sin barniz al interior y con un diámetro de $10 \mathrm{~cm}$ que hace pensar en una forma cerrada tipo guttus o lekitos $\mathrm{y}$, el segundo, un pie de campaniense $\mathrm{C}$, de pasta gris y barniz negro de tacto jabonoso, con decoración en la parte superior del fondo a base de acanaladuras y estrías a ruedecilla, probablemente una copa Lamb. 17/F 1255a que podría fecharse a mediados del siglo I a.C. (Gamo y Azcárraga 2012). A estos materiales hay que añadir fragmentos de ánforas tipo Dressel 1 y los característicos bordes de tipo ilduratin de grandes recipientes para almacenamiento. De este yacimiento procede posi- 
blemente una inscripción paleohispánica sobre un monetiforme de plata (Almagro 2003: 208209; $n^{\circ}$ 102; Gamo 2014: 37-41, $n^{\circ} 4$ ).

Así mismo se ha propuesto la existencia de un campamento romano tardorrepublicano al sureste del Cerro de la Virgen de la Muela, en la margen izquierda del Tajo (Bernárdez y Guisado 2016: 246), quizás vinculado al conflicto sertoriano.

El interés del yacimiento es que tuvo continuidad hasta la época romana imperial. En otros oppida indígenas como por ejemplo
Numantia (Jimeno et alii 2012) o Termes (Mangas y Martínez 2004) también la ciudad romana se superpone al antiguo asentamiento celtíbero. Entre los siglos I-II d.C. se desarrolló una ciudad a tenor de las relevantes estructuras de carácter urbano, observadas en nuestra prospección, que obtuvo la promoción jurídica posiblemente en época Flavia. La dispersión de materiales en superficie, así como los abundantes restos constructivos permiten afirmar que en esta época la extensión de Caraca alcanzó una superficie de al menos 8 ha.

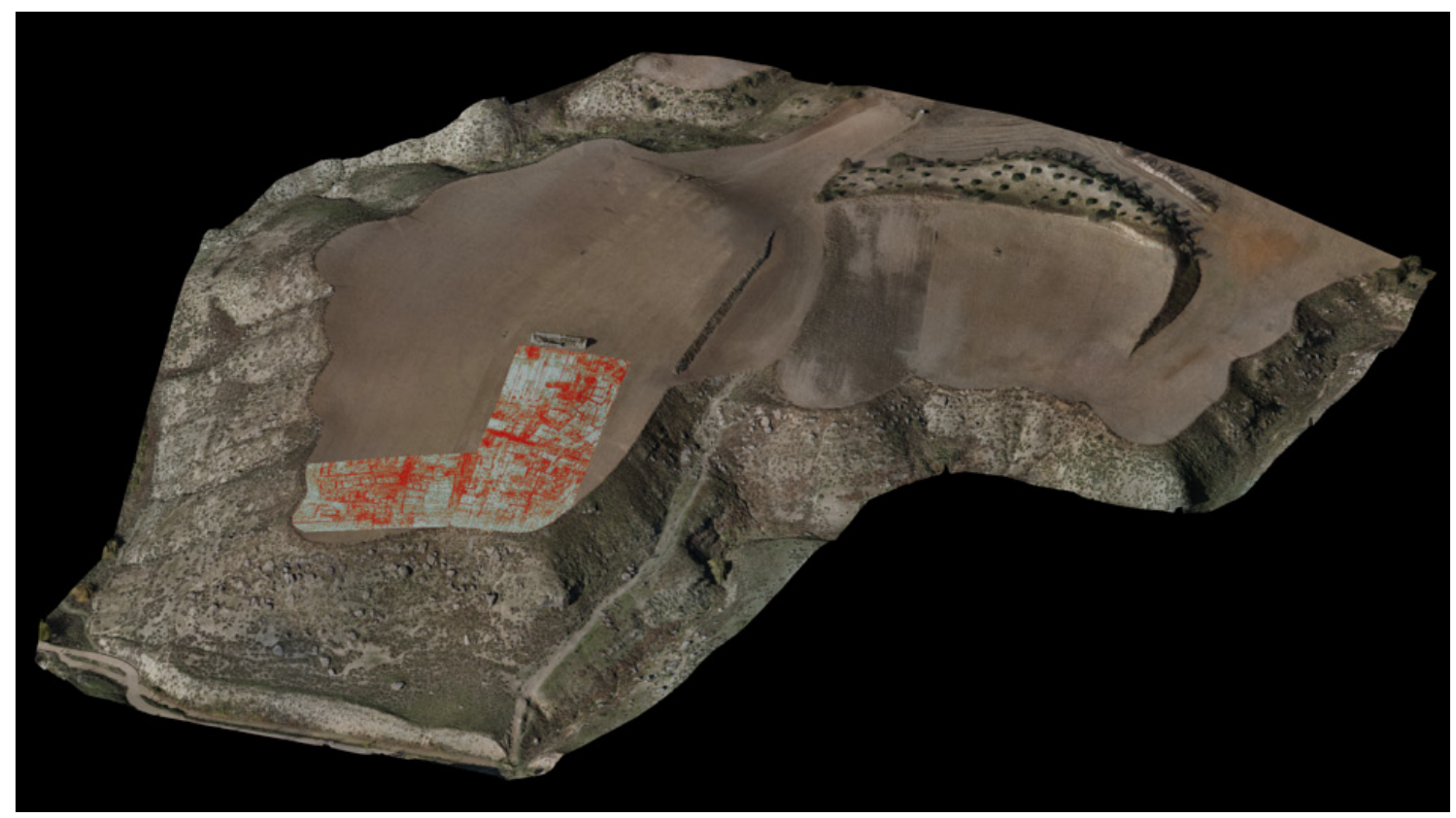

Figura 5. Vista del Cerro de la Virgen de la Muela y ubicación del área prospectada con georradar.

Creemos que esta ciudad es la Caraca de los carpetanos citada por Ptolomeo (Geografia, 2, 6, 56), así como por el Anónimo de Rávena $(313,10)$ por su posición en la vía Complutum-Carthago Nova, entre Complutum y Segobriga, como ya propuso Abascal (1982: 79-80), considerando que este yacimiento que se encuentra prácticamente equidistante de Complutum y Segobriga en línea recta. Quizás este asentamiento fuera también la Caraca tomada por Sertorio en el 77 a.C. (Plutarco, Sertorio, 17, 1-13), considerando la existencia de un campamento romano de esta época junto al Tajo, en las cercanías del Cerro de la Virgen de la Muela (Bernárdez y Guisado 2016: 246). La ubicación de Caraca ha sido objeto de debate científico desde el siglo XVI como hemos tra- tado monográficamente en otro trabajo (Gamo 2018: 269).

El topónimo Caraca es prerromano y etimológicamente relacionado con el propio nombre de los carpetanos según García Alonso (2008: 350). Este topónimo se ha interpretado que está presente en una tésera de Sasamón -Burgos- (Villar 1995; Untermann 1997: K.14.2), aunque existen opiniones contrarias (Torija y Baquedano 2007: 279-280, n 5).

La división provincial de Augusto incluyó estos territorios en la provincia imperial Hispania Citerior (Dion Cassio, 53, 12), también conocida como Tarraconensis (Plinio, Historia natural, 3, 1, 6; Ptolomeo, Geografía, 2, 6; Pomponio Mela, 2, 87; Suetonio, Vidade Galba, 8). El territorio de Caraca lindaba al oeste con 
Titulcia, al este con Ercavica, al noroeste con Complutum y al sureste con Segobriga. Esta ciudad se encontraba en un área limítrofe entre el Conventus Caesaraugustanus y el Carthaginiensis. Las fuentes clásicas no aluden a que conventus pertenecía Caraca y la respuesta no es sencilla pues Segobriga era del Carthaginiensis (Plinio, Historia natural, 3, 25) y Titulcia también según Knapp (1992: 170). Por otra parte Ercavica y Complutum pertenecían al Caesaraugustanus (Plinio, Historia natural, $3,24)$.

Los materiales romanos que hemos documentado fueron muy variados. En superficie pudimos observar numerosísimos restos constructivos: tegulae (algunas con decoración), estucos (con pintura mural y con molduras), basas y fustes de columnas, así como sillares yesíferos almohadillados de grandes dimensiones. En el Museo de Guadalajara se conservan así mismo un conjunto de estucos con pintura mural que parecen corresponder a uno o varios zócalos de una pared de un ambiente doméstico datable a finales del siglo I d.C., que parece que imitan la decoración con placas de mármol $\left(\mathrm{n}^{\circ}\right.$ inventario Museo: 1413). En el cerro también se ubica una ermita construida en parte con sillares y columnas romanas reutilizadas.

Otro elemento que ratifica la existencia de un municipio romano es la presencia de un acueducto. En el paraje de El Canalejo, al norte del Cerro de la Virgen de la Muela hemos documentado 112,9 $\mathrm{m}$ de itinerario de un acueducto de opus caementicium (Gamo et alii 2017). El caput aquae de la edificación sería el manantial de Lucos, a $3 \mathrm{~km}$ de la ciudad. La construcción de éste tipo de obras iba en consonancia con la monumentalización de las urbes con estatus municipal (Sánchez y Gozalbes 2012: 22).

En la posible necrópolis altoimperial de la ciudad, ubicada en la Dehesa de la Algarga en Illana (CIL II 5858; Gamo 2012: 168-169, $\mathrm{n}^{\mathrm{o}}$ 77), sobre la margen izquierda del Tajo y en las cercanías del Cerro de la Virgen de la Muela, se documentó un epígrafe funerario ${ }^{7}$ datable en el siglo II d.C. con mención a una mujer que posiblemente había sido sierva pública (Crespo 1998: 148, n $^{\circ} 48$ ). Lo cual es otro dato para confirmar la existencia de un núcleo urbano altoimperial promocionado jurídicamente.

Más esquiva ha sido la epigrafía latina en la propia ciudad, pues se limita a dos grafitos, uno sobre un fragmento de tégula del que quedan dos letras ("AE[...?]") y otro sobre un bor- de de T. S. H. en el que se lee: "[...E?]ION" (Gamo 2012: 135-136, nº 54 y 55).

El material más abundante es la cerámica. Sánchez-Lafuente (1982) publicó un nutrido conjunto de materiales altoimperiales que se conservan en el Museo de Guadalajara e incluye: Terra Sigillata Itálica (Fondo con sello "in planta pedis" de "(CN)? ATEI MA(HETIS)?" y un fragmento de borde de la forma Godineau 27), Gálica (Formas: Drag. 29, Drag. 37, Drag. 24/25, Drag. 15/17, Drag. 27, Ritterling 5), e Hispánica (Lisa y decorada de las formas: Drag. 29, Drag. 37, Drag. 27, Drag. 35, Hispánica 4), cerámicas pintadas de tradición indígena (Producciones altoimperiales de la Meseta Sur), cerámica de paredes finas, pondus, estucos, fragmentos de vidrio y un as de Calígula. El material cerámico altoimperial tiene similar cronología y características a los recogidos en nuestras prospecciones, destacando en estas la distribución zonal anteriormente comentada y la aparición en nuestras prospecciones de algunos elementos novedosos concentrados al sur de la ermita: cerámica de paredes finas, sigillata marmorata sudgálica (Formas Drag. 15/17 y 27), cerámica común romana (tipo Vegas 1), un asa de lucerna, así como fragmentos de T.S.H. decorada con medallones en los que se inserta una victoria alada.

Abascal (1986: 377, no 503) mencionó la presencia en este yacimiento de cerámica pintada de tradición indígena. Se trata de vasos globulares de labio sencillo (Forma 18A) de las producciones altoimperiales de la Meseta Sur. Se han realizado análisis arqueométricos (Difracción de rayos X, microscopía electrónica de barrido y microanálisis de rayos $\mathrm{X}$ ) en un fragmento de cerámica romana de tradición indígena decorado con bandas de color negruzco procedente de este yacimiento (Rincón 1986). Estos muestran que fue cocida en una atmósfera predominantemente oxidante, a una temperatura menos de $850^{\circ} \mathrm{C}$, el pigmento de la banda negruzca pudo ser una espinela de óxidos de hierro y manganeso.

$\mathrm{El}$ as de Calígula ( $\mathrm{n}^{\mathrm{o}}$ inventario Museo: ARQ 6273) muestra en el anverso la cabeza del emperador a izquierda con la leyenda: C CAESAR AVG GERMANICVS PON M TR POT. En el anverso Vesta sentada a izquierda, portando pátera y cetro, con la leyenda: VESTA/S C. Está datada entre el 37-38 d.C. (RIC I 38; Cohen 1892: n 27). Así mismo en el Museo de Guadalajara se conservan algunos objetos de bronce de este yacimiento: un aplique 
de asa, una arandela y un pasador. Por su parte González (1999: 25-26) mencionó el hallazgo en este yacimiento de fíbulas de tipo Aucissa, romboidales y leontimorfas.

Los mencionados fragmentos de vidrio se datan dentro de un arco cronológico de los siglos I-II d.C. incluyendo cuencos de costillas $\mathrm{y}$ fragmentos de ungüentario de tendencia globular, así como un galbo de color ámbar decorado con motivo zoomorfo (Ayllón y Oller 2001). En nuestras prospecciones también hemos podido documentar fragmentos de vidrio de forma indeterminada.

En el entorno de Caraca se documentan desde época altoimperial una serie de villae en la vega de Tajo, en clara relación con la ciudad, como la villa de la Vega Alcorisa o Alóciga (Sánchez-Lafuente 1982: 109), Las Peñas en Mazuecos (Gamo 2012: 184-186, n 89-90) o asentamientos rurales como Los Guillares de Almoguera datado en el siglo II d.C. (Vara y Martínez 2015: 34, n. 3).

El esparto y el lapis specularis fueron con seguridad recursos explotados en este enclave. La artesanía del esparto ha sido tradicional en esta área (Castellote 2006: 339-370), de lo que tenemos noticias en las Relaciones Topográficas de Felipe II (Pérez Villamil 1914). El esparto fue muy apreciado en época protohistórica así como romana y tuvo múltiples usos: utillaje naval, esteras, sacos, alpargatas, techumbres (Lillo 1985), poleas y espuertas para la minería... De hecho, se ha puesto en relación la vía Complutum-Carthago Nova con el transporte del esparto de las zonas interiores hacia Carthago Nova (Palomero 1987: 224), que sería el punto de exportación de esta mercancía desde época púnica (Apiano, Iberia, 10; Plinio, Historia natural, 19, 26-30; Livio, Ab urbe condita, 22, 20, 3; Strab., Geografia, 3, 4, 9; Trogo Pompeyo, 44, 1-2).

Durante las prospecciones han sido registrados fragmentos de lapis specularis en el yacimiento y existen vetas de éste tipo de yeso en el término. Es destacable la referencia de Plinio (Historia natural, 36, 160) que sitúa a Segobriga como centro de un complejo minero cuyo radio alcanzaba 100.000 pasos romanos, unos $147 \mathrm{~km}$. El cerro de la Virgen de la Muela se halla a $40 \mathrm{~km}$ de la anterior, pudiendo ser un centro urbano vinculado a la actividad minera. La explotación sistemática del espejuelo tuvo un origen en época de Augusto y la decadencia de la extracción coincidiría con los emperadores Adriano y Trajano, siendo sustituida por el vidrio (Bernárdez y Guisado 2012). Los materiales localizados en la superficie del yacimiento indican que el poblamiento del lugar no permanece, al parecer, más allá del siglo II d.C., quizás en relación con la decadencia de estas explotaciones.

Tampoco hemos podido documentar restos de época tardoantigua en el yacimiento, aunque hay que señalar que al pie del cerro contiguo está documentada una necrópolis de esa cronología (Sánchez-Lafuente 1982: 109).

En nuestras prospecciones encontramos un único fragmento de cerámica islámica con el exterior melado y el interior decorado en verde y manganeso sobre blanco, estilo de Medina Azahara, datada en el siglo $\mathrm{X}^{8}$.

En el Cerro de la Virgen de la Muela se conservan los restos de una ermita epónima quizás de origen medieval y en su ladera dice la tradición que fue encontrada tras la Reconquista la mencionada virgen (patrona de Driebes) por un pastor de Estremera, sobre una muela de molino (Murillo y Ballesteros 1985: 54; López de los Mozos 2015) y anualmente los vecinos de la localidad realizan una romería hasta este lugar. Esta edificación aparece citada en el siglo XVI en las Relaciones Topográficas de Felipe II (Pérez Villamil 1914).

Localizamos al sur de la ermita durante nuestras prospecciones cerámica de los siglos XVI y XVII, así como un fragmento de cerámica de superficies blancas con círculo azul de Paterna o Manises datada en el siglo XV.

\section{Consideraciones finales}

La relevante información recabada durante nuestros trabajos permite afirmar que el Cerro de la Virgen de la Muela estuvo ocupado reiteradamente desde el Bronce Final por un asentamiento tipo "poblado de ribera" a continuación situamos los materiales de la I Edad de Hierro, y un oppidum carpetano, romano republicano y posteriormente una ciudad altoimperial, llamada Caraca, de 8 ha de extensión, con foro, Cardo, Decumanus, posibles termas y un acueducto. Todo ello tiene un gran interés pues permite documentar en un mismo lugar la evolución de la cultura carpetana desde sus orígenes hasta su inclusión en la órbita romana. Por otra parte, la existencia de este oppidum sirve para contextualizar el tesoro de Driebes, cuya interpretación sigue siendo objeto de intensos debates. 
Los interesantes datos obtenidos mediante la prospección sistemática sin sondeos y geofísica muestran las buenas posibilidades interpretativas de las nuevas tecnologías aplicadas a la arqueología. Dada la entidad del yacimiento hemos planteado un proyecto de investigación arqueológica que permita, mediante campañas de excavación sistemática, completar la información aportada por todos estos hallazgos.

\section{Notas}

1. Agradecemos a M. L. Cerdeño (U.C.M.-Departamento de Prehistoria) sus comentarios acerca de esta publicación.

2. En algunas publicaciones existe una confusión entre el Cerro de la Virgen de La Muela de Driebes y el Despoblado de Santiago Vilillas en el término de Almoguera, citándose ambos como si fueran el mismo. Esta confusión puede estar motivada por la relativa cercanía entre los dos yacimientos que son, sin embargo, diferentes. Santiago Vilillas perteneció, por donación de Alfonso VIII, a la Orden de Calatrava, al igual que toda la comunidad de Almoguera (Ranz et alii 2009: 174-175).

3. Queremos agradecer a los profesores J. M. Abascal y J. Sánchez-Lafuente su amable colaboración aportándonos interesantes informaciones acerca de sus trabajos arqueológicos en este yacimiento.

4. Subvención a Proyectos de investigación del patrimonio arqueológico, paleontológico de Castilla la Mancha para 2016 (DOCM n ${ }^{\circ} 172$ de 2 de Septiembre de 2016). Expediente: 16.1448. Directores: E. Gamo y J. Fernández. Miembros del equipo: J. Sánchez, D. Cordero, S. Martin, D. Álvarez. Noviembre 2016.

5. Proyecto de prospección arqueológica sin sondeos para la documentación del Acueducto Romano de Driebes (Guadalajara). Junta de Comunidades de C-LM. Expediente: 161742-P1. Directores: E. Gamo y J. Fernández. Diciembre 2016.

6. Abascal (1983: 74, n 19) siguiendo a Hübner y Vives propuso la siguiente lectura: "FAVSTAE / PVB. / VERECUNDAE / PENTILIA".

7. Agradecemos a M. A. Cuadrado, conservador del Museo de Guadalajara, sus indicaciones acerca de las cerámicas de época medieval y moderna.

\section{Bibliografía}

Abascal, J. M., (1982): Vías de comunicación romanas de la Provincia de Guadalajara, Guadalajara.

—, (1983): "Epigrafía romana de la provincia de Guadalajara", Wad-Al-Hayara, 10: 49-115.

-, (1986): La cerámica pintada romana de tradición indígena en la Península Ibérica, Madrid. Almagro, M., (1977): "La iberización de las zonas orientales de la Meseta", en Simposio Internacional Els origens del mon iberic, Ampurias, 38-40: 93-156.

-, (2003): Epigrafia prerromana, Real Academia de la Historia, Madrid.

— y Almagro, M., (1964): "El Tesorillo de Valeria”, Numisma, 14, 71: 25-47.

-; Cano, J. J.; Ortega, J., (1999): "El anillo argénteo del Cerro de la Mesa (Toledo) y los anillos con caballito de la Hispania prerromana", Complutum, 10: 157-165.

— y Dávila, F., (1995): "El área superficial de los oppida en la Hispania céltica", Complutum, 6: 209-233.

Angoso, C. y Cuadrado, E., (1981): "Fíbulas ibéricas con escenas venatorias", Boletín de la Asociación Española de Amigos de la Arqueología, 13: 18-30.

Arribas, A. y Tarradell, M., (1987): "El Foro de Pollentia. Noticias de las primeras investigaciones", en Los foros romanos de las provincias occidentales, Madrid: 121-136.

Ayllón, M. J.; Oller, A., (2001): "Vidrio romano en Guadalajara: Driebes y Hortezuela de Océn”, en Jornadas sobre el vidrio de la España romana, Fundación Centro Nacional del Vidrio, La Granja: 431-432.

Azcárraga, S., (2015): El ocaso de un pueblo. La Carpetania centro-septentrional entre la Segunda Edad del Hierro y la Época romana: El valle bajo del Henares, Zona Arqueológica 18, Alcalá de Henares.

Barril, M., (2010): “Tesoros de plata en el ámbito celtibérico ¿función votiva, depósitos de platero o dinero fraccionario?", en Burillo, F. (ed.), VI Simposio sobre Celtíberos: Ritos y Mitos, Zaragoza: 7386.

Barroso, R. M., (2002): El Bronce Final y los comienzos de la Edad del Hierro en el Tajo Superior, Universidad de Alcalá, Alcalá de Henares.

Beltrán, M., (1991): Celsa. Guías arqueológicas de Aragón, Zaragoza. 
Bernárdez, M. J. y Guisado, J. C., (2012): "El distrito minero romano de lapis specularis de Castilla-La Mancha", en Orejas, A. y Rico, C. (coords.), Minería y Metalurgia Antiguas. Visiones y Revisiones (Homenaje a Claude Domergue), Casa de Velázquez, Madrid: 183-199.

- y Guisado, J.C., (2016): "El comercio del lapis specularis y las vías romanas en Castilla-La Mancha", en Carrasco, G. (ed.), Vías de comunicación romanas en Castilla-La Mancha, Universidad de Castilla-La Mancha, Cuenca: 231-276.

Castellote, E., (2006): Artesanías tradicionales de Guadalajara, Aache, Guadalajara.

Cerdeño, M. L. y Gamo, E., (2014): “Celtíberos y carpetanos: ¿frontera cultural, lingüística y étnica?”, en Baquedano, E. (ed.), I Simposio sobre los carpetanos. Arqueología e historia de un pueblo de la Edad de Hierro, Zona Arqueológica, 17, Museo Arqueológico Regional, Alcalá de Henares: 267-278.

Chaves, F., (2012): "Plata, guerra y sociedad: Iberia, finales del siglo III a. C.-inicios II a. C.", en Asolati, M. y Gorini, G. (eds.), I ritrovamenti monetali e i processi storico-economici nel mondo antico, Numismatica Patavina, 12, Eseda Editrice, Padua: 151-190.

- y Pliego, R., (2015): Bellum et argentum. La Segunda Guerra púnica en Iberia y el conjunto de monedas y plata de Villarrubia de Los Ojos (Ciudad Real), Universidad de Sevilla, Sevilla.

Cohen, H., (1892): Description Historique des monnaies frappées sous l'Empire Romain, Paris.

Crespo, S., (1998): "Los Publicii de Hispania romana: las fuentes epigráficas", Hispania Antiqua, 22: 139156.

De Ruyt, C., (1983): Macellum: marché alimentaire des Romains, Institut supérieur d'archéologie et d'histoire de l'art, Collège Érasme, Louvain-La-Neuve.

Galán, E. y Ruiz-Gálvez, M., (1996): “Divisa, dinero y moneda. Aproximación a los patrones petrológicos prehistóricos peninsulares", Complutum Extra, 6, 2: 151-165.

Gamo, E., (2012): Corpus de inscripciones latinas de la provincia de Guadalajara, Diputación de Guadalajara, Guadalajara.

—, (2014): Epigrafia paleohispánica entre Carpetania y Celtiberia, La Ergástula, Madrid.

-, (2015): La romanización de los pueblos de la Meseta oriental: arqueología y fuentes escritas, Tesis doctoral, directoras: M. L. Cerdeño y R. M. Sanz, Universidad Complutense de Madrid, Madrid.

-, (2018): La romanización de celtíberos y carpetanos en la Meseta oriental, Zona Arqueológica 22, Museo Arqueológico Regional, Alcalá de Henares.

- y Azcárraga, S., (2012): “Cerámica de barniz negro de época romana republicana en yacimientos celtibéricos y carpetanos de la provincia de Guadalajara", Lucentum, 31: 131-146.

—; Fernández, J.; Sánchez, J., (2017): “El abastecimiento de agua a la ciudad romana del Cerro de la Virgen de la Muela (Driebes, Guadalajara)", Veleia, 34, 237-247.

García Valero, M. A., (2002): "El Paleolítico en Guadalajara”, en García, E. y García, M. A. (eds.), Actas del I Simposio de Arqueología de Guadalajara, Madrid: 145-186.

García Alonso, J. L., (2008): "Romanización y celtización en la toponimia de la Meseta Sur”, en Carrasco, G. (coord.) La romanización en el territorio de Castilla-La Mancha, Universidad de Castilla-La Mancha, Cuenca: 339-366.

García-Bellido, M. P., (1999): "Sistemas metrológicos. Monedas y desarrollo económico", en Burillo, F. (ed.), IV Simposio sobre los celtíberos. Economía, Zaragoza: 363-385.

-, (2007): "Numismática y territorios étnicos en la Meseta Meridional", en Carrasco, G. (coord.), Los pueblos prerromanos en Castilla-La Mancha, Universidad de Castilla-La Mancha, Cuenca: 199-226.

García Riaza, E., (2006): "La expansión romana en Celtiberia", en Burillo, F. (ed.), Segeda y su contexto histórico. Entre Catón y Nobilior (195 al 153 a.C.), Zaragoza: 81-94.

Gómez, L., 2013: "Revisión interpretativa y cronológica de las termas de Baelo Claudia: nuevas propuestas", Antiquitas, 25: 165-176.

González, C., (1999): Fíbulas en la Carpetania, Ed. Decex, Madrid.

Gozalbes, E., 2008: "La presencia púnica en la meseta sur y los antecedentes de la conquista romana", en Carrasco, G. (coord.), La romanización en el territorio de Castilla-La Mancha, Universidad de Castilla-La Mancha, Cuenca: 33-60.

Hildebrandt, H. J., (1984): "Die Münzen aus Caceres el Viejo”, en Ulbert, G., Cáceres el Viejo. Ein spätrepublikanisches Legionslager in Spanisch-Extremadura, Mainz (Madrider Beiträge, 11): 257-297.

Jiménez, J.L., (1987): "Los modelos constructivos en la arquitectura Forense de la Península Ibérica", en Los foros romanos de las provincias occidentales, Madrid: 173-177. 
Jimeno, A.; Chaín, A.; Quintero, S.; Liceras, R.; Santos, A., (2012): “Interpretación estratigráfica de Numancia y ordenación cronológica de sus cerámicas", Complutum, 23 (1): 203-218.

Knapp, R. C., (1992): Latin Inscriptions of Central Spain, University of California, Publications, Classical Studies $n^{\circ} 34$, Berkeley-Los Angeles.

Lillo, P. A., (1985): "La cultura ibérica en tierras murcianas", en VV.AA. (coords.), Arqueología del País Valenciano: panorama y perspectivas, Anejo de la Revista Lucentvm, Universidad de Alicante, Alicante: $697-720$.

López de los Mozos, J. R., (2015): "Descubrimientos casuales y apariciones portentosas. Papeles de fiesta”, Guadalajara Diario.es.

Lorrio, A.J., (2001): Ercavica, la muralla y la topografía de la ciudad, Madrid.

- y Sánchez, M. D., (2001): "Elementos de un taller de orfebre en Contrebia Carbica (Villas Viejas, Cuenca)", Lucentum, 19-20: 127-148.

— y Sánchez, M. D., (2015): "Nuevos anillos prerromanos con decoración ecuestre", en Aguilera, I.; Beltrán, F.; Dueñas, M. J.; Lomba, C.; Paz, J. Á. (eds.), De las ánforas al museo. Estudios dedicados a Miguel Beltrán Lloris, Zaragoza: 563- 575.

Mangas, J. y Martínez, S., (2004): "Nuevas inscripciones romanas de Termes (Tiermes, Soria)", Veleia, 21: 289-300.

Morena, J.A. y Moreno, A., (2010): “Apuntes sobre el urbanismo romano de Torreparedones (Baena, Córdoba)", en Las técnicas y las construcciones en la ingeniería romana. V Congreso de las Obras Públicas Romanas, Córdoba: 429-460.

-; Moreno, A.; Martínez, R.M., (2012): El macellum de la colonia Ituci Virtus Iulia (Torreparedones, Baena, Córdoba), Baena.

Murillo, R. y Ballesteros, P., (1985): Aproximación histórica a la Alcarria Baja, Diputación de Guadalajara, Guadalajara.

Otero, P., (2002): “Las monedas del tesoro de Driebes", en Barril, M. y Rodero, A. (dirs.), Torques. Belleza y poder, Ministerio de Educación, Cultura y Deporte, Madrid: 274-276.

Palomero, S., (1987): Las vías romanas en la provincia de Cuenca, Cuenca.

Pelletier, A.; Dardaine, S.; Sillières, P., (1987): "Le Forum de Belo: Decouvertes recentes", en Los foros romanos de las provincias occidentales, Madrid: 165-172.

Pérez-Villamil, M., (1914): Relaciones topográficas de España. Guadalajara y pueblos de su provincia con aumentos y con notas de D. Manuel Pérez Villamil, vol. 5 (Memorial Histórico Español 46), Madrid.

Raddatz, K., (1969): Die Schatzfunde der iberischen Halbinsel, Madrider Forschungen, 5, Walter de Gruyte \& Co., Berlín.

Ranz, J. A.; López De Los Mozos, J. R.; Remartínez, M. J., (2009): Despoblados de la provincia de Guadalajara, Caja de Guadalajara, Guadalajara.

RIC I=Sutherland, C. H. V. y Carson, R. A. G., (1984): The Roman Imperial Coinage, Volume I, From 31 $B C$ to $A D$ 69, Londres.

Rincón, J. M., (1986): “Caracterización arqueométrica de un fragmento de cerámica pintada procedente del cerro de la Virgen de la Muela (Driebes, Guadalajara). Apéndice II”, en Abascal, J. M., La cerámica pintada romana de tradición indígena en la Península Ibérica, Madrid: 305-311.

Río-Miranda, J. e Iglesias, M.G., (2002): "Las termas de la ciudad romana de Caparra", Ahigal (Revista cultural online), 10.

Ripollès, P. P.; Cores, G.; Gozalbes, M., (2009): "El tesoro de Armuña de Tajuña (Guadalajara). Parte I: las monedas", en Arévalo, A. (ed.), Actas del XIII Congreso Nacional de Numismática (Cádiz 22-24 de Octubre de 2007), Universidad de Cádiz, Madrid-Cádiz: 163-182.

Ruíz Zapatero, G., Märtens, G.; Contreras, M.; Baquedano, E., (2012): Los últimos carpetanos: el Oppidum de el Llano de la Horca (Santorcaz, Madrid), Museo Arqueológico Regional, Madrid.

- y Álvarez Sanchís, J., (2013): "Vacceos, vettones y carpetanos ante el ataque de Aníbal”, en Bendala, M.; Pérez, M.; Escobar, I. (coords.), Fragor Hannibalis: Aníbal en Hispania, Madrid: 334-355.

Sánchez, E. y Gozalbes, E., (2012): "Los usos del agua en la Hispania romana", Vínculos de Historia, 1: 11-29.

Sánchez-Lafuente, J., (1982): "Nuevos yacimientos romanos en la provincia de Guadalajara”, Wad-Al-Hayara, 9: 103-115.

San Valero, J., (1945): El tesoro preimperial de plata de Driebes, Informes y memorias arqueológicas, 9 , Ministerio de Educación, Madrid. 
Sanmartí, E., (1987): “El Foro de Ampurias”, en Los foros romanos de las provincias occidentales, Madrid: 55-60.

Sillières, P., (1997): Baelo Claudia. Una ciudad romana de la Bética, Madrid.

Stylow, A. U., (2005): "Fuentes epigráficas para la historia de la «Hispania ulterior» en época republicana", en Melchor, E.; Mellado, J. y Rodríguez, J. F., (Coords.), Julio César y Corduba: tiempo y espacio en la campaña de Munda (49-45 A. C.): Actas del Simposio organizado por la Facultad de Filosofía y Letras de la Universidad de Córdoba y el Departamento de Ciencias de la Antigüedad y de la Edad Media, Universidad de Córdoba, Córdoba: 247-262.

Torrecilla, A., (2007): “Aproximación al estudio de los macella romanos en Hispania”, Caesaraugusta, 78: 455-480.

Torres, J., (2013): La tierra sin límites. Territorio, sociedad e identidades en el valle medio del Tajo, sS. IX-I a.C., Zona Arqueológica 16, Alcalá de Henares.

Torija, A. y Baquedano, I., (2007): "Las tesserae de la Colección Cerralbo. Viejas conocidas, nuevas perspectivas", Palaeohispanica, 7: 269-336.

Untermann, J., (1997): Monumenta Linguarum Hispanicarum. IV Die tartessischen, keltiberischen und lusitanischen Inschriften, Wiesbaden.

Valiente, J.; Crespo, M.L.; Espinosa, C., (1986): "Un aspecto de la celtización en el alto y medio Henares. Los poblados de Ribera", Wad-al-Hayara, 13: 47-70.

Vara, C. y Martínez, J., (2015): "Primeros indicios de la necrópolis hispanovisigoda de El Soto (Illana, Guadalajara)", B.A.A.M.G.U., 6: 31-56.

Villar, F., (1995): Estudios de celtibérico y de toponimia prerromana, Acta Salmanticensia, Estudios Filológicos, 260, Universidad de Salamanca, Salamanca.

Villaronga, L., (1993): Tresors monetaris de la Península Ibérica anteriors a August: repertori i anàlisi, Barcelona. 